\title{
Family Context Assessment to Promote Language and Reading Abilities in 6-Year-Old Children
}

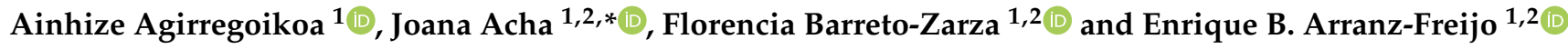 \\ 1 Department of Basic Psychological Processes and Its Development, Faculty of Psychology, \\ University of the Basque Country UPV/EHU, 20018 San Sebastian, Spain; ainhize.lopez@gmail.com (A.A.); \\ flor.barreto@ehu.eus (F.B.-Z.); e.arranzfreijo@ehu.eus (E.B.A.-F.) \\ 2 Biodonostia Health Research Institute, Group of Environmental Epidemiology and Child Development, \\ 20014 San Sebastian, Spain \\ * Correspondence: joana.acha@ehu.eus
}

Citation: Agirregoikoa, A.; Acha, J.; Barreto-Zarza, F.; Arranz-Freijo, E.B. Family Context Assessment to Promote Language and Reading Abilities in 6-Year-Old Children. Educ. Sci. 2021, 11, 26. https://doi.org/ 10.3390/educsci11010026

Received: 11 December 2020 Accepted: 8 January 2021 Published: 12 January 2021

Publisher's Note: MDPI stays neutral with regard to jurisdictional clai$\mathrm{ms}$ in published maps and institutional affiliations.

Copyright: (C) 2021 by the authors. Licensee MDPI, Basel, Switzerland. This article is an open access article distributed under the terms and conditions of the Creative Commons Attribution (CC BY) license (https:// creativecommons.org/licenses/by/ $4.0 /)$.

\begin{abstract}
Within a bioecological model, research works over the past decades have shown the significant influence of family micro systemic variables on child development. This study is aimed to test the factorial structure of the Haezi-Etxadi Family Assessment Scale (HEFAS-6), designed to detect protective family factors for language and reading development through the assessment of family context quality. The sample of this study consisted of 127 children aged 5 to 7 and their families. The factorial structure and the internal consistency of the data were analyzed. Results of the exploratory factor analysis (principal components with varimax rotation) showed the emergence of four factors: promotion of cognitive and linguistic development, promotion of socio-emotional development, family system strain and parental profile fostering child development. This structure was confirmed by confirmatory factor analysis. The internal consistency indices showed acceptable values. In conclusion, the tool shows good potential to assess the quality of the family context in the field of the promotion of reading and linguistic skills in educational, clinical and social intervention settings and through the implementation of evidence-based parenting policies.
\end{abstract}

Keywords: family context; scaffolding; linguistic development; reading

\section{Introduction}

Scientific evidence supports the strong influence that family context exerts on children's psychological development [1]. Although this impact is more evident in the first two years of life, it remains important during the later years of early childhood. Psychological development includes linguistic development and specifically the evolution of reading skills. In fact, it is between the ages of five and seven when the academic demand increases and, therefore, when difficulties related to the abilities involved in language and reading attainment become more evident. The aim of this work is to present a proposal, based upon a literature review, to properly assess family context variables, in order to support family-centered interventions to prevent and promote linguistic development and reading skills. The proposal is mainly centered in key family microsystemic variables within the framework of the bioecological model of Bronfenbrenner [2].

Starting the literature review within the field of family context variables promoting cognitive and linguistic development, it is relevant to highlight the fact that both domains are deeply interconnected. Evidence in the field of cognitive development shows the involvement of basic cognitive skills—attention, processing speed and working memory-in the development of phonological skills, such as phonological awareness or phonological memory, necessary for consequent linguistic development $[3,4]$ and literacy $[5,6]$. At the same time, family context variables can minimize or prevent difficulties both in the progress of basic cognitive skills as well as in the developmental trajectory of complex cognitive skills, including reading and language $[7,8]$. 
Within the above mentioned field, some studies have revealed the existence of a relationship between the quality of mother-child dyad interactions during shared reading and subsequent linguistic abilities during development [9-11]. These studies have shown that a series of scaffolding interactions such as describing text and images, and asking or requesting participation during reading, are associated with later vocabulary level and attitude towards reading, and to an optimal linguistic and reading developmental trajectory $[12,13]$. There is also evidence supporting the impact of maternal responsiveness and quality of maternal linguistic input on pre-academic skills of 4.5-year-old children [14].

Several works have revealed a different impact of specific interactions on children's linguistic skills during shared reading. For instance, using books to teach the alphabet is particularly associated with children's phonological awareness and, consequently, with their reading abilities, whilst linguistic scaffolding behaviors have a positive impact on children's vocabulary $[15,16]$. In addition, such impact is greater when the linguistic interaction is adapted to the developmental stage of the child, input frequency at 18 months, diversity at 30 months, and decontextualization at 42 months [17].

In addition to direct interactions, reading habits at home and parent reading history can influence the way in which children internalize reading habits and their motivation towards reading. Some evidence supporting this claim lies in the fact that children's exposure to storybooks is related to their level of receptive language, vocabulary and oral comprehension [18]. Some other studies have examined the role of the parental cognitive profile on phonological and reading skills from mid-childhood to early adolescence $[19,20]$, showing that parental literacy level and parents' reading habits are related to phonological and orthographic skills, as well as to children's reading fluency. In addition, these works point out that parental cognitive performance does not completely explain cognitive results, so that the context of family literacy and parental history, together with shared reading experiences, could play a pivotal role in the development of children's reading capacities.

In a complementary way, play can also be an enhancing variable for linguistic and reading development. It has been observed that the use of sophisticated vocabulary by adults during free play predicts reading comprehension and word recognition in the fourth grade, and that this relationship is mediated by the child's receptive vocabulary level in preschool $[21,22]$. In this line, some works also point to a contribution of the quality of interactions during play between fathers, mothers and children at home, to grammar development in infancy and reading level in fifth-grade children $[16,23]$. These findings show the importance of play as a learning tool during childhood, and of scaffolding behaviors during play as a source for the promotion of long-term language and reading attainment [24].

Within the field of family context variables promoting socio-emotional development, another set of studies show that an adequate emotional environment also promotes linguistic development beyond specific linguistic interactions; this is the case of a parental educational style that can be an important indicator of the context's potential for linguistic stimulation. More specifically, the existence of stable limits and the exercise of optimal frustration can directly impact the aspects related to self-regulation, and indirectly on cognitive competences involved in language and reading acquisition [25]. In this line, Hammer et al. [26] examined the association between parenting style, reading interactions and linguistic difficulties in a sample of 925 children, age 6, with Specific Language Impairment, suggesting that parenting practices and discipline, together with parental education and family socioeconomic status, were significantly related to language perception, fluency and articulation difficulties. In general, the existence in daily family life of both components of the so called democratic style, warmth and discipline, along with an appropriate scaffolding within the proximal development zone, are promotion factors of linguistic development throughout childhood [27].

Other socio-emotional variables such as the lack of affection, sensitivity and lack of optimal frustration, defined as an appropriate demand within the child's proximal development zone, are negatively related to children's linguistic level, whilst quality 
of interactions is positively related to children's language skills in mid-childhood [28]. Supporting this evidence, some recent studies suggest that discipline practices and optimal frustration can be specific key variables involved in the development of basic cognitive skills-attention, self-regulation, [29] and working memory [30], which condition the developmental trajectory of complex cognitive abilities such as language or reading [3]. Other works have obtained similar results emphasizing the role of emotional expressivity and self-esteem enhancement in language and reading development [31,32].

Regarding family context variables grouping the strain level inside the family system, several studies have shown that variables such as stress and marital conflict, as well as the lack of organization of daily life, can hamper the attentional development and self-regulation skills that are at the basis of the language learning processes [33,34]. For instance, Froyen et al. [35] explored in a sample composed of 385 mother-child dyads the role of marital satisfaction, emotional expressivity and home learning context in children's reading skills. Results showed that emotional expressivity was negatively influenced by variables related to tension in the family system such as stress, difficulty in resolving conflicts and low marital satisfaction. These variables have a specific negative impact on the development of executive functions involved in academic skills [30] and, ultimately, in linguistic and reading development $[36,37]$. These works confirm that high levels of family stress are associated with low levels of receptive and expressive vocabulary in primary school children.

Other group of variables related to parental characteristics have also shown an impact on linguistic development. The most important variable within this group is parental self-efficacy, which clearly influences the quality of scaffolding and parent-child interactions [38]. On one hand, a low perception of parental self-efficacy can lead parents to perceive their children as less competent and use inconsistent educational practices, aspects that can negatively influence general cognitive development. On the other hand, positive feelings of self-efficacy can lead to better parenting practices. For example, Shumow and Lomax [39] showed that parental self-efficacy predicted socio-emotional adjustment and academic achievement of primary school children, mediated by parenting behaviors such as involvement and monitoring. More recently, Hughes-Scholes and Gavidia-Payne [40] have shown the influence of a positive parental self-efficacy perception on developmental outcome of children with disabilities.

Parental knowledge about parenting and about developmental milestones is showing also an influence on child development [41,42] and specifically on literacy skills development; this was shown in the work by Rowe et al. [43] in which controlling for demographic factors, parenting knowledge on child development partially mediated the relation between parent education and child language and pre-literacy skills in four-year-old children.

In sum, there is ample evidence on the specific variables of family context that exert an influence in the developmental trajectory of linguistic and reading skills [27]. However, the way these variables are related to each other has not been yet explored [44], and to date, there is no tool that allows evaluating all variables at the same time. This fact justifies the design of a specific questionnaire which responds to this issue, including all the variables described above. With this aim, the Haezi-Etxadi Family Assessment Scale (HEFAS-6) was designed as an instrument aimed at assessing the quality of family context for children who start primary school with or without language or reading difficulties, by including all contextual variables associated with a better prognosis of linguistic and reading attainment. The purpose of the tool is twofold: (1) to facilitate the detection of contextual variables promoting or hindering reading and language abilities in mid-childhood; (2) to provide professionals who work with families a resource to comprehensively evaluate the development potential of family contexts, taking into account interactive and contextual variables from a bio-ecological framework. 


\section{Materials and Methods}

\subsection{Participants}

The sample used in the present study consisted of 127 families of 5 to 7 years old Spanish children ( $M=6$ years, 6 months, $S D=9.52$ months; $52.75 \%$ female, $47.25 \%$ male). Father's age ranged between 33 and 55 years $(M=42.57, S D=4.09)$ and mother's age was between 30 and 50 years $(M=40.45, S D=3.69)$. The sample was recruited from six public schools located in the suburban area of Bilbao (Basque Country), located in neighborhoods that correspond to an average socioeconomic profile. This information was gathered from a socio-demographic questionnaire created ad hoc to collect information about child's age, parent's age, level of education and socioeconomic level. The participating families signed an informed consent document approved by the Ethics Committee for Research related to Human Beings of the University of the Basque Country (EHU/UPV) ref. M10_2016_071MR1.

\subsection{Instruments}

Haezi-Etxadi Family Assessment Scale-6: it is a scale assessing family context variables that could influence basic cognitive skills involved in language development across the beginning of a child's schooling and adapted to six-year-old children, which specifically explores variables associated with language and reading abilities as reported in the literature. This scale has been adapted from a previous version designed to evaluate the family context of 2-year-old children [45] and 4-year-old children [46]. The proposals of the aforementioned scales and the HEFAS- 6 are based on classic family assessment tools, such as the HOME scale [47]. These tools have traditionally been used to assess families in at-risk contexts, and additionally they do not include variables related to scaffolding interactions or parental self-efficacy. The new scale provides an update of family context variables identified by recent research as influential in specific areas of language and reading development.

Each item that made up the original version was designed to measure specific competences, from which larger factors were extracted and placed within four subscales with factors influencing a child's development. The first subscale evaluates variables related to the promotion of cognitive and linguistic development (33 items). The main changes in the adapted version pertain to this subscale, by including 10 new items which were not present in the original scales, and which refer specifically to promotion of language and reading that were mentioned in the Section 1 (see also Supplementary Material). The items were judged by two independent experimenters and ten families to ensure their understanding and pertinence. Each item was scored from 1 to 5, and their inter-rater agreement reached $96 \%$.

The second subscale includes variables related to the promotion of socio-emotional development (28 items) and include items regarding variables mentioned in the Section 1 such as promotion of self-esteem, setting of limits, educational style, etc. No item was added or eliminated in this subscale. A third subscale evaluates variables related to the organization of the physical and social context (35 items), which explores variables related to parental stress, frequency and exposure to parental conflict or availability of adequate housing physical space. Twenty-seven items included in the third subscale of the original version were not included in this one since they were measuring family variables that have not been related to language and reading in the literature. These items were measuring father involvement, relation with extended family and stability of social and school relations (see Supplementary Material). This subscale was then redefined as family system strain.

The last subscale measures variables related to a parental profile fostering child development (24 items) and groups factors related to parent's knowledge about developmental stages, perception of parental self-efficacy and assertiveness. Given that this subscale includes both key variables, no item was therefore modified or added. The initial structure of the HEFAS- 6 is detailed in the Supplementary Material. The total amount of items once the 27 from the second subscale were removed was 120, although for better item identification, 
the original numbering was employed in the analysis. Each item was assessed using a Likert scale of six points, in terms of frequency (Never-Always) or level of agreement (Totally disagree-Totally agree).

\subsection{Procedure}

Each family completed the HEFAS-6 scale at home at the beginning of the school year (September-October). The examiner gave a copy of the scale in booklet format to each family in a school meeting, and parents were informed about the filling instructions and asked to take it home to fill it up. The booklet included the instructions for completing the questionnaire, as well as the contact information of the examiner so that the families could ask any questions that might arise. Parents had to indicate by a cross who completed the scale (in this case, the mother responded in $43.3 \%$ of the cases, the father in $9.4 \%$, and both of them completed the scale in $47.2 \%$ of the cases). Once all the questions had been answered, they had to take the booklet back to their school teachers so that it could be returned to the examiner. The estimated duration for completion of the scale was approximately $30 \mathrm{~min}$.

\section{Results}

\subsection{Exploratory Factor Analysis}

The first step of the statistical analysis was to perform an exploratory factor analysis of the original instrument using version 24 of the IBM SPSS, with the aim of eliminating all the items with low factorial weight $(<0.30)$, as well as those that compromised the reliability ( $\alpha$ coefficient) of each factor. Bartlett's sphericity tests were conducted for each subscale: Promotion of Cognitive and Linguistic Development (PCLD), Promotion of Socio-emotional Development (PSED), Family system strain (FSS) and Parental Profile Fostering Child Development (PPFCD). The results were statistically significant in all cases: $\operatorname{PCLD}\left(\chi^{2}=515,960\right.$ d.f. $\left.=190, p<0.000\right)$, PSED $\left(\chi^{2}=694,988\right.$ d.f. $\left.=210, p<0.000\right)$, FSS $\left(\chi^{2}=703,725\right.$ d.f. $\left.=136, p<0.000\right)$ and DEPP $\left(\chi^{2}=339,645\right.$ d.f. $\left.=66, p<0.000\right)$. Thus, the hypothesis that the correlation matrix was in fact an identity-based one could be dismissed. The KMO index revealed optimum values of $0.68,0.77,0.75$, and 0.75 , respectively. This enabled us to continue with the factor analysis through the extraction of the principal axes and varimax rotation. Results reflected the existence of four subscales and showed the suitability of 70 items. The resulting factors and the percentage of variance explained by each factor are presented in Table 1.

Table 1. Exploratory factor analysis on each subscale as criterion variable.

\begin{tabular}{lllll}
\hline SUBSCALE 1 & F1 & F2 & F3 & F4 \\
\hline Item 21 & 0.552 & & & \\
Item 23 & 0.434 & & & \\
Item 24 & 0.621 & & & \\
Item 25 & 0.763 & & & \\
Item 26 & 0.734 & & & \\
Item 27 & 0.640 & & & \\
Item 28 & 0.673 & 0.705 & & \\
Item 29 & & 0.614 & & \\
Item 30 & & 0.525 & 0.502 & \\
Item 31 & 0.615 & 0.644 & \\
Item 32 & & & 0.610 & \\
Item 4 & & & 0.553 & 0.530 \\
Item 5 & & & & \\
Item 14 & & & & \\
Item 20 & & & \\
Item 3 & & & \\
Item 6 & & & \\
Item 9 & & & & \\
\hline
\end{tabular}


Table 1. Cont.

\begin{tabular}{|c|c|c|c|c|}
\hline $\begin{array}{l}\text { Item } 17 \\
\text { Item } 18 \\
\text { Variance explained }\end{array}$ & $25.58 \%$ & $10.60 \%$ & $10.34 \%$ & $\begin{array}{l}0.511 \\
0.525 \\
10.16 \%\end{array}$ \\
\hline SUBSCALE 2 & F1 & F2 & F3 & \\
\hline Item 38 & 0.358 & & & \\
\hline Item 45 & 0.766 & & & \\
\hline Item 46 & 0.741 & & & \\
\hline Item 47 & 0.736 & & & \\
\hline Item 48 & 0.644 & & & \\
\hline Item 49 & 0.554 & & & \\
\hline Item 59 & 0.383 & & & \\
\hline Item 35 & & 0.594 & & \\
\hline Item 36 & & 0.540 & & \\
\hline Item 37 & & 0.507 & & \\
\hline Item 56 & & 0.653 & & \\
\hline Item 57 & & 0.508 & & \\
\hline Item 60 & & 0.565 & & \\
\hline Item 61 & & 0.555 & & \\
\hline Item 50 & & & 0.494 & \\
\hline Item 52 & & & 0.739 & \\
\hline Item 53 & & & 0.439 & \\
\hline Item 54 & & & 0.341 & \\
\hline Item 58 & & & 0.449 & \\
\hline Item 97 & & & 0.546 & \\
\hline Item 98 & & & 0.642 & \\
\hline Variance explained & $25.49 \%$ & $13.62 \%$ & $13.27 \%$ & \\
\hline SUBSCALE 3 & F1 & F2 & F3 & \\
\hline Item 8 & 0.725 & & & \\
\hline Item 65 & 0.331 & & & \\
\hline Item 66 & 0.759 & & & \\
\hline Item 99 & 0.584 & & & \\
\hline Item 107 & & 0.773 & & \\
\hline Item 108 & & 0.787 & & \\
\hline Item 109 & & 0.579 & & \\
\hline Item 111 & & 0.676 & & \\
\hline Item 112 & & 0.461 & & \\
\hline Item 113 & & & 0.674 & \\
\hline Item 114 & & & 0.846 & \\
\hline Item 115 & & & 0.831 & \\
\hline Item 116 & & & 0.756 & \\
\hline Item 117 & & & 0.789 & \\
\hline Item 119 & & & 0.488 & \\
\hline Item 120 & & & 0.591 & \\
\hline Item 121 & & & 0.625 & \\
\hline Variance explained & $24.41 \%$ & $16.49 \%$ & $14.03 \%$ & \\
\hline SUBSCALE 4 & F1 & F2 & & \\
\hline Item 124 & 0.639 & & & \\
\hline Item 125 & 0.717 & & & \\
\hline Item 126 & 0.744 & & & \\
\hline Item 127 & 0.528 & & & \\
\hline Item 128 & 0.724 & & & \\
\hline Item 129 & 0.669 & & & \\
\hline Item 140 & 0.499 & & & \\
\hline Item 141 & & 0.474 & & \\
\hline Item 144 & & 0.627 & & \\
\hline Item 145 & & 0.722 & & \\
\hline Item 146 & & 0.828 & & \\
\hline
\end{tabular}


Table 1. Cont.

\begin{tabular}{|c|c|c|}
\hline Item 147 & & 0.800 \\
\hline Variance explained & $27.66 \%$ & $23.38 \%$ \\
\hline
\end{tabular}

\subsection{Confirmatory Factor Analysis}

After completion of the exploratory factor analysis, the relevant confirmatory analysis (CFA) was carried out to validate the factorial structure of the instrument, using version 24 of the IBM SPSS Amos software. These analyses showed that the proposed structure of the scale was supported statistically although the organization of the items changed. The final structure of the scale can be found in the Supplementary Material.

In the first subscale, four factors emerged: reading habits at home (composed of 7 items), promotion of reading (consisting of 4 items), learning materials (composed of 4 items) and play (consisting of 5 items). The adjustment of this subscale was good $\left(\chi^{2}=213.232, g l=161, p=0.004, C M I N=1.324, C F I=0.878, R M S E A=0.051\right)$ and the contribution of each item to the factor can be seen in Figure 1.

The second subscale comprised three factors: optimal frustration, self-esteem and democratic educational style, all composed of 7 items. The adjustment of the subscale in this case was also good $\left(\chi^{2}=233.460, g l=183, p=0.007, C M I N=1.276, C F I=0.908\right.$, RMSEA $=0.047)$ and the independent contribution made by the items to each factor can be seen in Figure 2.

Regarding the third subscale, it presented a good fit $\left(\chi^{2}=142.93, g l=112, p=0.026\right.$, $C M I N=1.276, C F I=0.951, R M S E A=0.047)$ including the following three factors: quality of physical context (formed by 4 items), parental stress (composed of 5 items) and parental conflict (formed by 8 items). The contribution made for each item can be seen in Figure 3 .

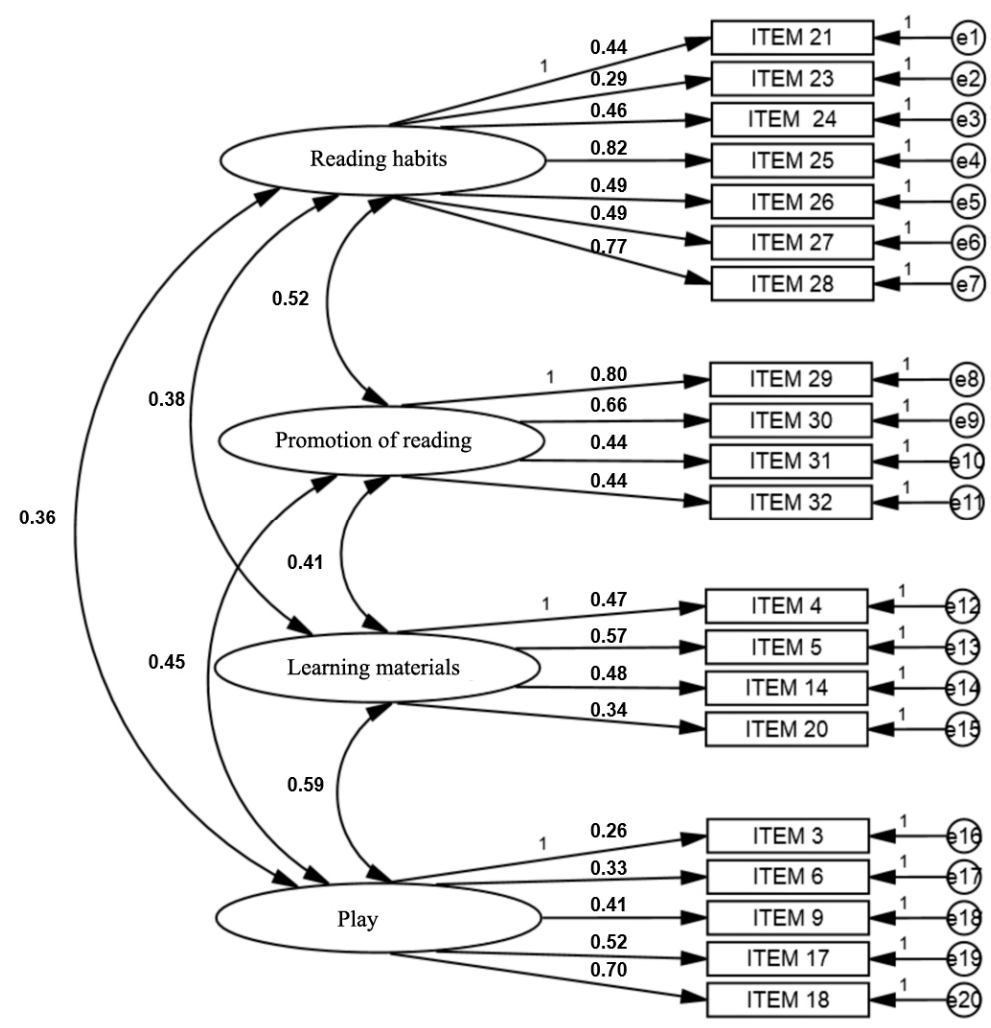

Figure 1. Confirmatory factorial analysis of subscale 1: promotion of cognitive and linguistic development. 


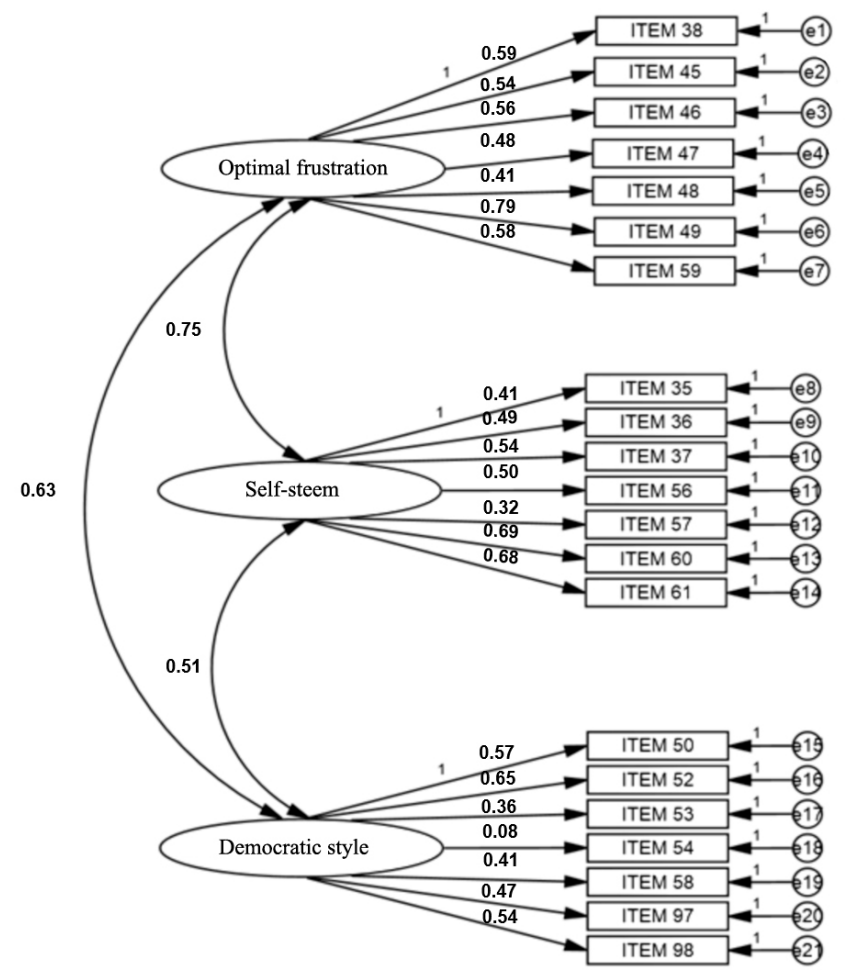

Figure 2. Confirmatory factorial analysis of subscale 2: promotion of socio-emotional development.

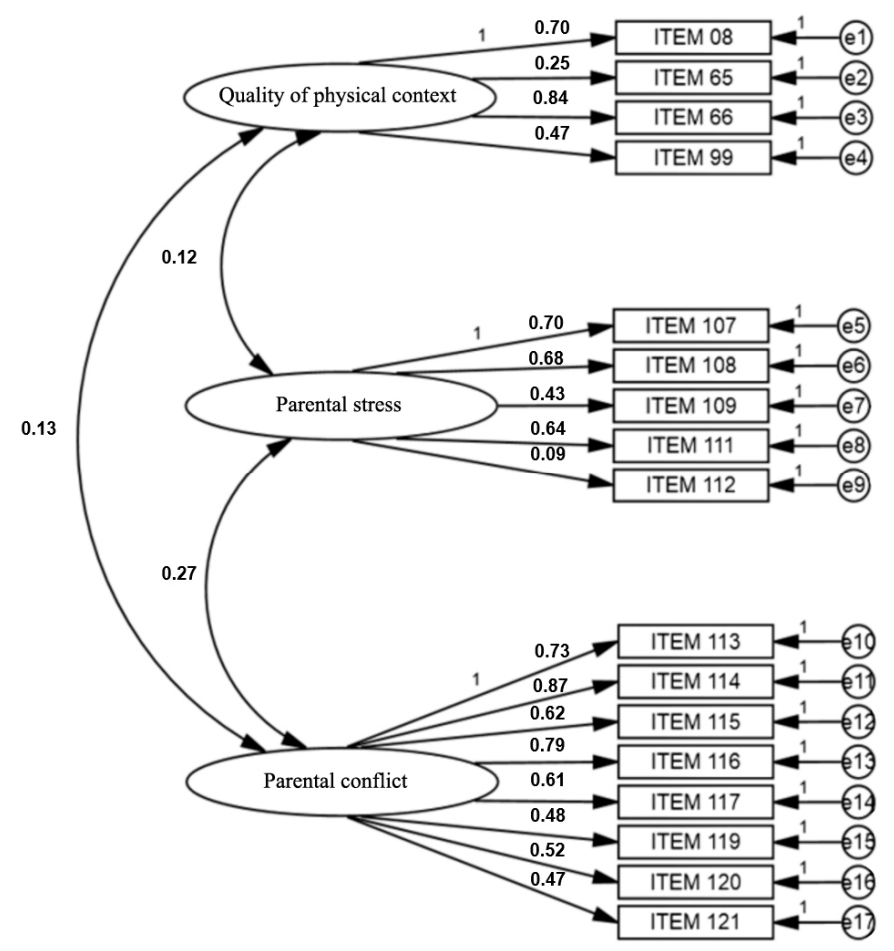

Figure 3. Confirmatory factorial analysis of subscale 3: Family system strain.

Finally, in the last subscale, two factors emerged, concretely, parental self-efficacy (composed of 7 items) and parent's knowledge about psychological development (composed of 5 items). The adjustment of this subscale was also good $\left(\chi^{2}=69.29, g l=52\right.$, $p=0.05, C M I N=1.333, C F I=0.945, R M S E A=0.051)$, and the independent contribution of each item is reflected in Figure 4. 


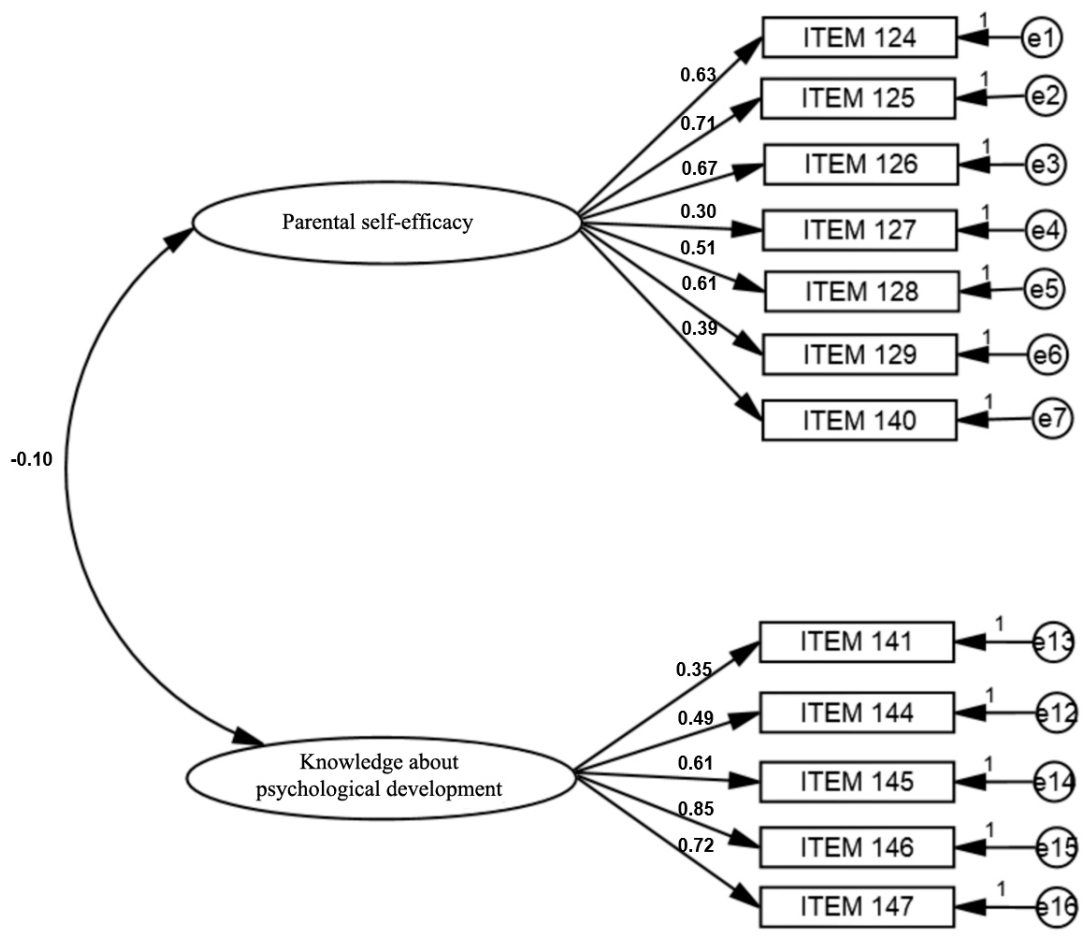

Figure 4. Confirmatory factorial analysis of subscale 4: Parental Profile Fostering Child Development.

\subsection{Internal Consistency}

Table 2 shows internal consistency values measured with Cronbach's alpha coefficients. As can be seen, alpha coefficients oscillate between 0.55 and 0.83 values and the vast majority of them were exceeding 0.60 , and only one factor in subscale one (learning materials) showed a lower index of reliability (Cronbach's alpha $=0.55)$. Global alpha scores of each subscale indicate good values $(0.77,0.81,0.76,0.75$ and 0.71 , respectively, for each subscale).

Table 2. Cronbach's alpha coefficients for the four subscales and corresponding factors.

\begin{tabular}{lc}
\hline Subscales and Factors & Cronbach's Alpha \\
\hline Subscale 1: Promotion of Cognitive and Linguistic Development & 0.77 \\
1.1. Reading habits at home & 0.77 \\
1.2. Promotion of reading & 0.67 \\
1.3. Learning materials & 0.55 \\
1.4. Promotion of play & 0.60 \\
\hline Subscale 2: Promotion of Socio-emotional Development & 0.81 \\
2.1. Optimal frustration & 0.75 \\
2.2. Self-esteem & 0.71 \\
2.3. Democratic educational style & 0.61 \\
\hline Subscale 3: Family System Strain & 0.75 \\
3.1. Quality of physical context & 0.62 \\
3.2. Parental stress & 0.62 \\
3.3. Parental conflict & 0.83 \\
\hline Subscale 4: Parental Profile Fostering Child Development & 0.71 \\
4.1. Parental self-efficacy & 0.75 \\
4.2. Knowledge about psychological development & 0.69 \\
\hline
\end{tabular}

\section{Discussion}

The new scale presented in this article arises as a result of the need to evaluate family context variables which, according to the recent empirical evidence, have an influence in 
basic cognitive skills involved in language development. It is worth noting that the scope of this instrument goes beyond the traditional family assessment procedure, based upon educational styles approach, and provides an in-depth and updated approach, including items measuring family variables regarding language and reading stimulation. For this reason, we added items related to variables that the former scales did not include. Specifically, in the first subscale, the new items aimed at capturing the existence of learning materials related to reading at home, reading habits in the family, and parent's language and reading scaffolding. Another challenge was to restrict the amount of items in the questionnaire, focusing on these variables that promote reading and language attainment. Therefore, a set of items related to social and emotional development were eliminated to shorten the questionnaire and limit it to the items that specifically measure the variables of interest reported in the introduction.

In relation to the structure of the scale, the exploratory and confirmatory factor analyses did not show a substantial variation in the structure of the proposed scale. In the first place, results showed the adequacy of eliminating the items that did not load in any factor in the previous exploratory analyses. As a result, a shorter version with four subscales emerged in the CFA. Concretely, these subscales combine respectively, factors related to the promotion of cognitive and linguistic development (subscale 1, 20 items), promotion of socioemotional development (subscale 2, 21 items), family system strain (subscale 3, 17 items) and parental profile fostering child development (subscale 4, 12 items). As seen, the main differences from the original HEFAS version is that questionnaires in the first subscale include the additional items related to reading habits and promotion of reading, and that subscale 3 is limited to factors related to the ability of the family to provide physical and psychological stability to the child, through an adequate physical context and relationships free of stress and conflict.

In general terms, the resulting tool showed a good fit, which indicates that it is sensitive to the variability of the family context and, in addition, the reliability indexes calculated using the alpha coefficient were acceptable for each of the scales, despite the fact that one factor of subscale one (learning materials) showed poorer value. A potential reason is the lower weight of this factor in the family organization of children at this age in relation to the other factors. Another reason could be the existence of lower answer variability in these factors due to the low item specificity to capture a particular construct or to the similar-medium to high-socio-economic level of the families. This fact, however, does not imply the invalidity of the items; rather their significant load to their respective factors contributes to the scale's reliability and consistency, and their elimination negatively influences the adjustment of the structure of the scale.

The included variables have a positive effect on the factors, delimiting the positive parenting curriculum according to the key variables cited in the introduction. For example, all the variables that positively load factors 1 to 4 reflect aspects related to the promotion of cognitive and linguistic development, and are grouped around four factors: reading habits at home, parent-driven motivation towards reading, learning materials and play behaviors at home. On the other hand, all the items related to promotion of socio-emotional development are grouped around three factors: optimal frustration, self-esteem and democratic educational style. The existence of a factor to represent the family system strain is based on the evidence that the items measure the quality of family environment. It is clear that the absence of toxic stress and the presence of good parental management of conflict are much more compatible with the existence of positive routines in daily family life [48].

Family routines are the main component of family structure and have been identified as a key positive variable in the field of parental education and children upbringing by the scientific literature [1,49]. The transcendence of routines comes from the fact that they provide consistency to the quality of family context (1) because repeated interactions leave a significant trace in a child's development and are, therefore, permanently internalized by the subject; (2) because their transversal nature affects all areas of parental competences and, therefore, becomes the essential diagnostic criterion of the quality of family context. 
A questionnaire like the one presented in this study specifically aims to identify the existence of stable routines as an empirical exponent of what is called a structured family context; (3) it should be highlighted that the establishment of routines is the cornerstone of any parenting program and, especially, of parenting programs aimed at children with developmental delays [50].

Some items are grouped around two factors that reflect the degree of perception of parental self-efficacy and the level of knowledge about infant developmental stages. These items capture important self-perception variables that can modulate the quality of responsiveness and language interactions, and thus can be key intervention targets [24,51]. Therefore, the resulting factors might be included in the subscale called parental profile fostering child development, replicating the structure of this same subscale in the original version.

The presented tool is a contribution to the rigorous development of positive parenting policies, which have been promoted at an international level intensively since the beginning of the 21st century. An essential feature of the positive parenting focus is the adoption of a non-deficit approach to both evaluation and family intervention. This view is based on the idea that all families have some strength that, precisely, should constitute the starting point of preventive or therapeutic interventions. The instrument presented in this study allows to identify the strengths and weaknesses of each family and, therefore, provides valuable information to design specific interventions by professionals in the educational, social and health fields. Finally, it should be noted that the use of this instrument for the evaluation of large populations can provide data for the accurate design of empowerment policies for families with children with some type of linguistic or reading delay.

This scale offers a novel and appropriate structure for evaluating concrete context variables that can enhance language and reading development but some limitations should be taken into account. Given the reduction of the length of the scale with respect to the original, it would be convenient to apply the scale to a larger sample size, in order to guarantee the test-retest reliability. Likewise, it would be convenient to analyze the performance of the instrument in a sample with greater variability in terms of SES, because previous works have found a strong association between socio-demographic variables and quality of family context [52]. Recent results point to the specific influence of maternal SES on children's cognitive development and, in particular, on executive functions [53], that are central to the development of phonological, linguistic and reading skills. An analysis of the relationships between SES and quality of family context is therefore relevant in order to adequately diagnose and plan preventive intervention in populations of families with a socio-demographic risk profile.

Supplementary Materials: Original scale structure and original items are available online at https: //www.mdpi.com/2227-7102/11/1/26/s1.

Author Contributions: Conceptualization: J.A. and E.B.A.-F.; methodology: A.A., J.A. and F.B.-Z.; validation: A.A. and J.A.; formal analysis: A.A. and J.A.; investigation: A.A., J.A., F.B.-Z. and E.B.A.-F.; data curation: A.A.; writing —original draft preparation: A.A. and J.A.; writing review and editing: J.A., F.B.-Z. and E.B.A.-F.; supervision: J.A., F.B.-Z. and E.B.A.-F.; project administration: J.A. and E.B.A.-F.; funding acquisition: A.A., J.A. and E.B.A.-F. All authors have read and agreed to the published version of the manuscript.

Funding: This research was supported by grant EJ-2016_1_0155/2017_2_0260.

Institutional Review Board Statement: The study was conducted according to the guidelines of the Declaration of Helsinki, and approved by the Institutional Review Board (or Ethics Committee) of the Universidad del País Vasco UPV/EHU, project approval reference M10_2016_071MR1_ACHA MORCILLO, and has been partially supported by grant EJ-2016_1_0155/2017_2_0260.

Informed Consent Statement: Informed consent was obtained from all subjects involved in the study.

Data Availability Statement: The data presented in this study are available on request from the corresponding author. The data are not publicly available due to the privacy of the information provided by participants with respect to the specific educational, social and family context. 
Acknowledgments: The authors acknowledge the invaluable help of all the children and families that willingly have taken part on this study.

Conflicts of Interest: The authors declare no conflict of interest.

\section{References}

1. Fiese, B.H.; Fisher, M. Family Context in Early Childhood Education. In Handbook of Research on the Education of Young Children; Saracho, O.N., Ed.; Routledge: Charlotte, NC, USA, 2019.

2. Rosa, E.M.; Tudge, J. Urie Bronfenbrenner's Theory of Human Development: Its Evolution From Ecology to Bioecology. J. Fam. Theory Rev. 2013, 5, 243-258. [CrossRef]

3. Gray, S.; Green, S.; Alt, M.; Hogan, T.; Kuo, T.; Brinkley, S.; Cowan, N. The Structure of Working Memory in Young Children and Its Relation to Intelligence. J. Mem. Lang. 2017, 92, 183-201. [CrossRef] [PubMed]

4. Verhagen, J.; Leseman, P. How Do Verbal Short-Term Memory and Working Memory Relate to the Acquisition of Vocabulary and Grammar? A Comparison between First and Second Language Learners. J. Exp. Child Psychol. 2016, 141, 65-82. [CrossRef] [PubMed]

5. Blankenship, T.L.; Slough, M.A.; Calkins, S.D.; Deater-Deckard, K.; Kim-Spoon, J.; Bell, M.A. Attention and Executive Functioning in Infancy: Links to Childhood Executive Function and Reading Achievement. Dev. Sci. 2019, 22, e12824. [CrossRef]

6. Valdois, S.; Roulin, J.L.; Bosse, M.L. Visual Attention Modulates Reading Acquisition. Vision Res. 2019, 165, 152-161. [CrossRef]

7. La Paro, K.M.; Justice, L.; Skibbe, L.E.; Pianta, R.C. Relations among Maternal, Child and Demographic Factors and the Persistence of Preschool Language Impairment. Am. J. Speech-Lang. Pathol. 2004, 13, 291-303. [CrossRef]

8. Tulviste, T.; Tamm, A. Informal Language Stimulation Rather than Corrective Feedback Matters in Estonian Children's Language Performance. Learn. Instr. 2019, 63, 101221. [CrossRef]

9. Laakso, M.L.; Poikkeus, A.M.; Lyytinen, P. Shared Reading Interaction in Families with and without Genetic Risk for Dyslexia: Implications for Toddlers' Language Development. Infant Child Dev. 1999, 8, 179-195. [CrossRef]

10. Hood, M.; Conlon, E.; Andrews, G. Preschool Home Literacy Practices and Children's Literacy Development: A Longitudinal Analysis. J. Educ. Psychol. 2008, 100, 252-271. [CrossRef]

11. Niklas, F.; Wirth, A.; Guffler, S.; Drescher, N.; Ehmig, S.C. The Home Literacy Environment as a Mediator between Parental Attitudes toward Shared Reading and Children's Linguistic Competencies. Front. Psychol. 2020, 11, 1628. [CrossRef]

12. Rochanavibhata, S.; Marian, V. Maternal Scaffolding Styles and Children's Developing Narrative Skills: A Cross-Cultural Comparison of Autobiographical Conversations in the US and Thailand. Learn. Cult. Soc. Interact. 2020, 26, 100413. [CrossRef] [PubMed]

13. Weigel, D.J.; Martin, S.S.; Bennett, K.K. Contributions of the Home Literacy Environment to Preschool-aged Children's Emerging Literacy and Language Skills. Early Child Dev. Care 2006, 176, 357-378. [CrossRef]

14. Wade, M.; Jenkins, J.M.; Venkadasalam, V.P.; Binnoon-Erez, N.; Ganea, P.A. The Role of Maternal Responsiveness and Linguistic Input in Pre-Academic Skill Development: A Longitudinal Analysis of Pathways. Cogn. Dev. 2018, 45, 125-140. [CrossRef]

15. Rowe, M.L. A Longitudinal Investigation of the Role of Quantity and Quality of Child-Directed Speech in Vocabulary Development. Child Dev. 2012, 83, 1762-1774. [CrossRef] [PubMed]

16. Noble, C.H.; Cameron-Faulkner, T.; Lieven, E. Keeping It Simple: The Grammatical Properties of Shared Book Reading. J. Child Lang. 2018, 45, 753-766. [CrossRef] [PubMed]

17. Galende, N.; Sánchez de Miguel, M.; Arranz, E. The Role of Parents' Distancing Strategies in the Development of Five-Year-Old Children's Theory of Mind. Early Child Dev. Care 2012, 182, 207-220. [CrossRef]

18. Farrant, B.M.; Zubrick, S.R. Parent-child Book Reading across Early Childhood and Child Vocabulary in the Early School Years: Findings from the Longitudinal Study of Australian Children. First Lang. 2013, 33, 280-293. [CrossRef]

19. Van Bergen, E.; Bishop, D.; van Zuijen, T.; de Jong, P.F. How Does Parental Reading Influence Children's Reading? A Study of Cognitive Mediation. Sci. Stud. Read. 2015, 19, 325-339. [CrossRef]

20. Wirth, A.; Ehmig, S.C.; Drescher, N.; Guffler, S.; Niklas, F. Facets of the Early Home Literacy Environment and Children's Linguistic and Socioemotional Competencies. Early Educ. Dev. 2020, 31, 892-909. [CrossRef]

21. De la Rie, S.; Van Steensel, R.C.M.; van Gelderen, A.J.S.; Severiens, S. The Role of Type of Activity in Parent-child Interactions within a Family Literacy Programme: Comparing Prompting Boards and Shared Reading. Early Child Dev. Care 2018, 188, 1076-1092. [CrossRef]

22. Yogman, M.; Garner, A.; Hutchinson, J.; Hirsh-Pasek, K.; Golinkoff, R.M. The Power of Play: A Pediatric Role in Enhancing Development in Young Children. Pediatrics 2018, 142, e20182058. [CrossRef] [PubMed]

23. Cook, G.A.; Roggman, L.A.; Boyce, L.K. Fathers' and Mothers' Cognitive Stimulation in Early Play with Toddlers: Predictors of 5th Grade Reading and Math. Fam. Sci. 2011, 2, 131-145. [CrossRef]

24. Burgoyne, K.; Gardner, R.; Whiteley, H.; Snowling, M.J.; Hulme, C. Evaluation of a Parent-delivered Early Language Enrichment Programme: Evidence from a Randomised Controlled Trial. J. Child Psychol. Psychiatry 2018, 59, 545-555. [CrossRef] [PubMed]

25. Schroeder, V.M.; Kelley, M.L. Associations between Family Environment, Parenting Practices, and Executive Functioning of Children with and without ADHD. Ournal Child Fam. Stud. 2009, 18, 227-235. [CrossRef]

26. Hammer, S.; Tomblin, J.B.; Zhang, X.; Weiss, A.L.C. Relationship between Parenting Behaviours and Specific Language Impairment in Children. Int. J. Lang. Commun. Disord. 2001, 36, 185-205. [CrossRef] 
27. Madigan, S.; Prime, H.; Graham, S.A.; Rodrigues, M.; Anderson, N.; Khoury, J.; Jenkins, J.M. Parenting Behavior and Child Language: A Meta-Analysis. Pediatrics 2019, 144, e20183556. [CrossRef]

28. Nguyen, T.; Schleihauf, H.; Kayhan, E.; Matthes, D.; Vrtička, P.; Hoehl, S. Neural Synchrony in Mother-Child Conversation: Exploring the Role of Conversation Patterns. Soc. Cogn. Affect. Neurosci. 2020, nsaa079. [CrossRef]

29. Baker, S.; Morawska, A.; Mitchell, A. Promoting Children's Healthy Habits through Self-Regulation via Parenting. Clin. Child Fam. Psychol. Rev. 2019, 22, 52-62. [CrossRef]

30. Bernier, A.; Carlson, S.M.; Deschênes, M.; Matte-Gagné, C. Social Factors in the Development of Early Executive Functioning: A Closer Look at the Caregiving Environment. Dev. Sci. 2012, 15, 12-24. [CrossRef]

31. Carta, J.J. Effects of Parenting on Young Children's Language and Communication. In Handbook of Parenting and Child Development Across the Lifespan; Sanders, M., Morawska, A., Eds.; Springer: Cham, Switzerland, 2018; pp. 201-215.

32. Molfese, V.J.; Modglin, A.; Molfese, D.L. The Role of Environment in the Development of Reading Skills: A Longitudinal Study of Preschool and School-Age Measures. J. Learn. Disabil. 2003, 36, 59-67. [CrossRef]

33. Harris, A.W.; Henry, C.S.; Liu, C.; Morris, A.S. Family Resilience: The Power of Rituals and Routines in Family Adaptive Systems. In APA Handbooks in Psychology ${ }^{\circledR}$. APA Handbook of Contemporary Family Psychology: Foundations, Methods, and Contemporary Issues across the Lifespan; Fiese, B.H., Celano, M., Deater-Deckard, K., Jouriles, E.N., Whisman, M.A., Eds.; American Psychological Association: Washington, DC, USA, 2018; pp. 223-239. [CrossRef]

34. Peterson, C.C.; Riggs, J.; Guyon-Harris, K.; Harrison, L.; Huth-Bocks, A. Effects of Intimate Partner Violence and Home Environment on Child Language Development in the First 3 Years of Life. J. Dev. Behav. Pediatr. 2019, 40, 112-121. [CrossRef] [PubMed]

35. Froyen, L.C.; Skibbe, L.E.; Bowles, R.P.; Blow, A.J.; Gerde, H.K. Marital Satisfaction, Family Emotional Expressiveness, Home Learning Environments and Children's Emergent Literacy. J. Marriage Fam. 2013, 75, 42-55. [CrossRef]

36. Noel, M.; Peterson, C.; Jesso, B. The Relationship of Parenting Stress and Child Temperament to Language Development among Economically Disadvantaged Preschoolers. J. Child Lang. 2008, 35, 823-843. [CrossRef] [PubMed]

37. Willard, J.A.; Hammer, C.S.; Bitetti, D.; Cycyk, L.M.; Leyendecker, B. Mothers' Depressive Symptoms and Their Children's Turkish Heritage Language Vocabulary Development. Int. J. Biling. 2019, 23, 71-86. [CrossRef]

38. Hohlfeld, A.S.; Harty, M.; Engel, M.E. Parents of Children with Disabilities: A Systematic Review of Parenting Interventions and Self-Efficacy. Afr. J. Disabil. 2018, 7, 1-12. [CrossRef]

39. Shumow, L.; Lomax, R. Parental Efficacy: Predictor of Parenting Behavior and Adolescent Outcomes. Parent. Sci. Pract. 2002, 2, 127-150. [CrossRef]

40. Hughes-Scholes, C.H.; Gavidia-Payne, S. Early Childhood Intervention Program Quality: Examining Family-Centered Practice, Parental Self-Efficacy and Child and Family Outcomes. Early Child. Educ. J. 2019, 47, 719-729. [CrossRef]

41. Karuppannan, A.; Ramamoorthy, T.; Rammamoorthi, A. Mother's Knowledge on Child's Developmental Milestones and Parenting Skills in Kanchipuram District, Tamilnadu-a Descriptive Cross Sectional Study. Int. J. Health Sci. Res. 2020, 10, $242-247$.

42. Scarzello, D.; Arace, A.; Prino, L.E. Infant Behavior and Development Full Length Article Parental Practices of Italian Mothers and Fathers during Early Infancy: The Role of Knowledge about Parenting and Child Development. Infant Behav. Dev. 2016, 44, 133-143. [CrossRef]

43. Rowe, M.L.; Denmark, N.; Harden, B.J.; Stapleton, L.M. The Role of Parent Education and Parenting Knowledge in Children's Language and Literacy Skills among White, Black, and Latino Families. Infant Child Dev. 2016, 25, 198-220. [CrossRef]

44. Rindermann, H.; Baumeister, A.E.E. Parents' SES vs. Parental Educational Behaviour and Children's Development: A Reanalysis of the Hart and Risley Study. Learn. Individ. Differ. 2015, 37, 133-138. [CrossRef]

45. Velasco, D.; de Miguel, M.S.; Egurza, M.; Arranz, E.; Aranbarri, A.; Fano, E.; Ibarluzea, J. Family Context Assessment in a Public Health Study. Gac. Sanit. 2014, 28, 356-362. [CrossRef] [PubMed]

46. de Miguel, M.S.; Baigorri Zia, P.; Barreto, F.B.; Santa-Marina, L.; Arranz-Freijo, E.B. Positive Parenting Assessment in 4 Year Old Children. Early Child Dev. Care 2020, 1-17. [CrossRef]

47. Bradley, R.H.; Caldwell, B.M. The HOME Inventory and Family Demographics. Dev. Psychol. 1984, 20, 315-320. [CrossRef]

48. Branco, M.S.S.; Linhares, M.B.M. The Toxic Stress and Its Impact on Development in the Shonkoff's Ecobiodevelopmental Theorical Approach. Estud. Psicol. 2018, 35, 89-98. [CrossRef]

49. Reay, T. Family Routines and Next-Generation Engagement in Family Firms. Entrep. Theory Pract. 2019, 43, 244-250. [CrossRef]

50. Ibañez, L.V.; Kobak, K.; Swanson, A.; Wallace, L.; Warren, Z.; Stone, W.L. Enhancing Interactions during Daily Routines: A Randomized Controlled Trial of a Web-based Tutorial for Parents of Young Children with ASD. Autism Res. 2018, 11, 667-678. [CrossRef]

51. Neuhauser, A.; Ramseier, E.; Schaub, S.; Burkhardt, S.C.; Lanfranchi, A. Mediating Role of Maternal Sensitivity: Enhancing Language Development in at-Risk Families. Infant Ment. Health J. 2018, 39, 522-536. [CrossRef]

52. Davis-Kean, P.E. The Influence of Parent Education and Family Income on Child Achievement: The Indirect Role of Parental Expectations and the Home Environment. J. Fam. Psychol. 2005, 19, 294-304. [CrossRef]

53. Daneri, M.P.; Blair, C.; Kuhn, L.J.; Investigators, F.K. Maternal Language and Child Vocabulary Mediate Relations Between Socioeconomic Status and Executive Function During Early Childhood. Child Dev. 2019, 90, 2001-2018. [CrossRef] 